\title{
Modified expression to evaluate the correlation coefficient of dual hesitant fuzzy sets and its application to multi-attribute decision making
}

\author{
Akanksha Singh ${ }^{1}$ \\ ${ }^{1}$ Thapar Institute of Engineering and Technology
}

July 7, 2020

\begin{abstract}
Ye (Appl. Math. Model. 38 (2014) 659-666) proposed an expression for evaluating the weighted correlation coefficient between two dual hesitant fuzzy sets (DHFSs). Ye claimed that their proposed expression can be used for finding the solution for several real-life multi-attribute decision making (MADM) problems under dual hesitant fuzzy set (DHFS) environment. To validate the claim, Ye solved one real-life problem (finding the best investment company). In future, other researchers may use Ye's expression for solving same type of real-life problems or some other type of real-life problems. However, after a deep study, it is observed that Ye has used some mathematical incorrect assumptions to obtain his proposed expression i.e., Ye's expression is not valid in its present form. Therefore, if one will apply this expression then the obtained results may or may not be exact. Keeping the same in mind, Ye's expression has been modified. Furthermore, using the modified expression, the exact result of the real-life problem, considered by Ye, has been obtained.
\end{abstract}

\section{Hosted file}

manuscript.docx available at https://authorea.com/users/340658/articles/467766-modifiedexpression-to-evaluate-the-correlation-coefficient-of-dual-hesitant-fuzzy-sets-and-itsapplication-to-multi-attribute-decision-making 